\title{
¿Arte?, ¿documento?, ¿política? La construcción de memoria en el cortometraje alrededor del 68 mexicano
}

\author{
Javier Cossalter \\ Instituto de Historia del Arte Argentino y Latinoamericano "Luis Ordaz", \\ Facultad de Filosofía y Letras, Universidad de Buenos Aires. CONICET. \\ javiercossalter@gmail.com \\ ORCID: https://orcid.org/0000-0001-5660-6704 \\ Fecha de finalización: 12 de febrero de 2021 \\ Recibido: 22 de marzo de 2021 \\ Aceptado: 11 de mayo de 2021. \\ DOI: https://doi.org/10.26422/aucom.2021.1001.cos
}

\section{Resumen}

El cortometraje moderno latinoamericano participó de forma activa en las transformaciones del campo cultural regional entre las décadas del 50 y del 70, caracterizado por la experimentación estética, la intermedialidad y la efervescencia social. La imbricación entre arte y política suscita una serie de reflexiones en torno al film breve alrededor del 68 mexicano, objeto de estudio del presente artículo. En este sentido, el trabajo aborda los cortometrajes Comunicados cinematográficos del Consejo Nacional de Huelga (Paul Leduc y Rafael Castanedo, 1968) y Mural efímero (Raúl Kamffer, 1968-1973) con el propósito de analizar su estatuto de obra estética, agente de la historia y documento social. En este caso, el registro (audio)visual de una movilización y de un acto artístico performático no solo evidencia la voluntad comunicacional de la instancia de producción en un período cercano al de su concepción, sino que vislumbra el anhelo por construir una memoria del presente. Asimismo, la eficacia de la imagen visual en tanto documento histórico -y, por ende, su carácter mnemónico- se manifiestan en la conformación de una tradición visual y en la recuperación y puesta en valor patrimonial de estas obras, desde entonces hasta la actualidad. Por tal motivo, el artículo examina también un film mexicano contemporáneo que retoma las imágenes acerca del movimiento estudiantil, con la intención de confirmar tales premisas.

Palabras clave: cortometraje, cine mexicano, documento, memoria.

\section{Art? Document? Political statement? The construction of memory in short films about the Mexican Movement of 1968}

\section{Abstract}

Latin American short films played an active role in transforming the local cultural field between the 1950s and 1970s. These works were characterized by aesthetic experimentation, intermedi- 
ality, and social effervescence. Their interweaving of art and politics led us to reflect upon certain short films made about the Mexican Movement of 1968, which are the topic of this paper: Comunicados cinematográficos del Consejo Nacional de Huelga (Paul Leduc and Rafael Castanedo, 1968) and Mural efímero (Raúl Kamffer, 1968-1973). We analyzed them as aesthetic works, historical agents, and social documents. In (audio)visually recording a social mobilization and a performative artistic act, respectively, they reveal the communicational intent behind their productions (which, in both cases, followed shortly after their initial conceptions). They also suggest a desire to build a memory of the present. The effectiveness of the visual image as an historical document - and, therefore, its mnemonic character - is demonstrated by the ensuing development of a visual tradition and the ongoing restoration and promotion of these works due to their historical importance. In order to confirm these ideas, we also examine a contemporary Mexican film that looks back at images of 1968's student movement.

Key words: short film, Mexican cinema, document, memory.

\section{Arte? Documento? Política? A construção da memória no curta em torno do mexicano 68}

\section{Resumo}

O curta-metragem latino-americano moderno participou ativamente das transformações do campo cultural regional entre as décadas de 1950 e 1970, caracterizadas pela experimentação estética, a intermedialidade e a efervescência social. $\mathrm{O}$ entrelaçamento entre arte e política suscita uma série de reflexões sobre o curta-metragem em torno do mexicano 68, objeto de estudo deste artigo. Nesse sentido, a obra aborda os Comunicados cinematográficos del Consejo Nacional de Huelga (Paul Leduc e Rafael Castanedo, 1968) e o Mural efímero (Raúl Kamffer, 1968-73) com o objetivo de analisar seu estatuto de obra estética, agente da história e documento social. Nesse caso, o registro (audio) visual de uma mobilização e de um ato artístico performático não só mostra a vontade comunicacional da instância de produção em um período próximo ao de sua concepção, mas também vislumbra o desejo de construir uma memória do presente. Da mesma forma, a eficácia da imagem visual como documento histórico e, portanto, seu caráter mnemônico, se manifestam na conformação de uma tradição visual e na recuperação e valorização dessas obras, desde então até o presente. Por isso, o artigo examina também um filme mexicano contemporâneo que retoma imagens sobre o movimento estudantil, com o intuito de confirmar essas premissas. Palavras chave: curta-metragem, cinema mexicano, documento, memória.

\section{Introducción ${ }^{1}$}

Entre mediados de la década del 50 y mediados de la del 70, el campo cultural latinoamericano vivenció un proceso de reconfiguración que implicó, en términos generales, dos grandes premisas: un marcado afán modernizador y una paulatina agitación social que desembocó en una radicalización política. Es por ello que, de acuerdo con Claudia Gilman (2003), podemos caracterizar a este período en la región desde

\footnotetext{
Este artículo es el resultado de una estadía de investigación realizada en la Filmoteca de la Universidad Nacional Autónoma de México en enero de 2020, en el marco del proyecto de investigación "El film de corta duración en América Latina. Reconfiguración del campo cinematográfico durante los inicios del cine moderno”, financiado por la Agencia Nacional de Promoción Científica y Tecnológica, Fondo para la Investigación Científica y Tecnológica (FONCYT).
} 


\section{Austral Comunicación \\ Volumen 10, número 1 (junio de 2021): 183-206 ISSN (I) 2313-9129. ISSN (E) 2313-9137}

la noción de época, en tanto conciencia de una sociedad que comparte un horizonte esperado de transformaciones en el campo de la cultura y que establece el discurso de lo deseable. Este entramado impactó de forma manifiesta en el terreno de las artes a través del dinamismo y de la intermedialidad entre las disciplinas, la experimentación estética y un profundo compromiso social. En el campo cinematográfico, el cortometraje, gracias a su marginalidad, sus posibilidades económicas y potencialidades estructurales de aprehensión del receptor se convirtió en un medio eficaz para la exploración del lenguaje y en un vehículo funcional dentro de un contexto particular de convulsión social. Ahora bien, este no solo se erigió como un dispositivo de registro para la acción inmediata, sino que también vislumbró una orientación hacia la conformación de un patrimonio audiovisual y la construcción de memoria(s).

No obstante, si bien esta coyuntura es común a gran parte de los países latinoamericanos, cada uno desarrolló un camino singular acorde al devenir histórico local. ${ }^{2}$ Este escrito estará focalizado en México, en torno a ciertas producciones cinematográficas alrededor del 68 mexicano. En este sentido, se abordarán los cortometrajes Comunicados cinematográficos del Consejo Nacional de Huelga (Paul Leduc y Rafael Castanedo, 1968) y Mural efímero (Raúl Kamffer, 1968-1973) con el propósito de analizar su doble estatuto de obra estética y documento social. ${ }^{3} \mathrm{El}$ registro audiovisual de una movilización o de un acto artístico performático no solo evidencia la voluntad comunicacional de la instancia de producción en un contexto inmediato a su concepción y la condición de la obra como agente de la historia (Ferro, 1980), sino que deja entrever la necesidad de edificar memoria. Asimismo, la eficacia de la imagen visual en tanto documento histórico (Burke, 2005) y, por ende, su carácter mnemónico se pueden apreciar en la recuperación y puesta en valor patrimonial de las obras señaladas, ya sea en un plano temporal cercano al de su producción como en la contemporaneidad.

Para llevar a cabo tales objetivos, hemos dividido el trabajo en tres secciones. La primera estará dedicada a plantear el panorama cultural en México, que incluye la modernización del cine y de las artes, la conjunción del arte y la política y la participación activa de entidades de carácter universitario. El segundo bloque estará centrado en el análisis de las dos obras escogidas, las cuales serán estudiadas en función de las variables arte/documento, teniendo en cuenta los hechos históricos acaecidos y el corpus general de producciones cinematográficas en el que se insertan. Finalmente, el tercer y último apartado estará reservado para asentar el potencial carácter mnemónico de estas obras en la conformación de un patrimonio del presente (Colin, 2014), mediante

\footnotetext{
2 En trabajos previos hemos estudiado de forma comparada la injerencia del film de corta duración en el terreno de la experimentación y la politización en las cinematografías de América Latina. Para profundizar en estas cuestiones, véase Cossalter $(2017 ; 2018 ; 2019 ; 2020)$.

3 Ambos cortometrajes se encuentran disponibles para su visualización en el canal de YouTube de la Filmoteca de la Universidad Nacional Autónoma de México.
} 
Javier Cossalter

¿Arte?, ¿documento?, ¿política? La construcción de memoria en el cortometraje alrededor del 68 mexicano

la reactivación de estas imágenes ya sea en producciones de la época como en películas actuales. Se hará un breve comentario sobre la extensa tradición iconográfica generada alrededor del 68 mexicano y se tomará un caso puntual -Trazos en trozos: Mural efímero, México 68 (María Judith Alanís Figueroa, 2008)- que nos permite ratificar el compromiso patrimonial de aquellos productos audiovisuales inaugurales y asignarles un sentido fundacional en cuanto a la memoria visual de un acontecimiento determinante en términos históricos.

\title{
Nuevos agentes, instituciones y expresiones. El campo cultural y cinematográfico mexicano entre las décadas del 50 y del 70
}

Luego de la Segunda Guerra Mundial, y de la mano de la Comisión Económica para América Latina (CEPAL), se arribó al consenso de que el crecimiento económico en la región llegaría por medio de la vía de la industrialización, camino iniciado por algunos países latinoamericanos años atrás. El modelo económico entonces predominante en los años posteriores fue el denominado desarrollismo, que tuvo su repercusión -en mayor o menor medida- al interior de los respectivos campos culturales.

\begin{abstract}
Miguel Alemán, en línea con lo que la CEPAL apoyaba, llegó a la presidencia de México en 1946, con un programa económico que hizo hincapié en la producción industrial mediante el apoyo decidido del Estado y el fomento a la inversión privada internacional para el desarrollo de sectores productivos. (Galindo, 2017, p. 18) ${ }^{4}$
\end{abstract}

De acuerdo con Carlos Monsivais (1976), el desarrollismo cultural llegaría a ese país tiempo después, puesto que, según su parecer, es en los 60 cuando la cultura pasa a ser considerada como una herramienta para garantizar la modernidad. Si bien esto resulta evidente, ya para la década del 50 podemos hallar algunas marcas que evidencian una renovación en el terreno cultural mexicano. En este sentido, destacamos la aparición de diversos suplementos culturales en la revista Siempre! y en los periódicos Novedades y El Nacional, junto con la tarea desempeñada por la Coordinación de Difusión Cultural de la Universidad Nacional Autónoma de México (UNAM) -creada a fines de la década del 40 y de gran injerencia en el futuro inmediato- y la Radio UNAM, que entre 1953 y 1965 "colaboraba con la circulación del arte y la cultura emergente, y el fortalecimiento de la crítica, no solo en el ámbito literario sino también en el terreno del cine" (Cossalter, 2018, p. 20). En la esfera de las artes plásticas, fue la Generación de la ruptura la que renovó, a través del neofigurativismo y la abstracción, la escena visual mexicana, dominada por el muralismo bajo el sustento de la Escuela Mexicana de Pintura. Frente al nacionalismo exacerbado promovido por esta, los ar-

El desarrollismo estabilizador, tal como se conoció en aquel país, continuó bajo las presidencias de Adolfo Ruiz Cortines (1952-1958) y Adolfo López Mateos (1958-1964). 


\section{Austral Comunicación \\ Volumen 10, número 1 (junio de 2021): 183-206 ISSN (I) 2313-9129. ISSN (E) 2313-9137}

tistas de la ruptura incentivaron, desde espacios de consolidación privados, un proceso internacionalista que recién encontraría legitimación estatal en el decenio siguiente. ${ }^{5}$ Por otra parte, a finales de los 50, la juventud mexicana dio un giro hacia el existencialismo, en tanto una forma de resistencia que tiempo después se etiquetó como la "contracultura". Esta impactó de modo singular en el terreno de la música, ya sea de la mano del rock and roll y el movimiento beat, como también en relación con el jazz y el surgimiento de los cafés existencialistas. ${ }^{6}$

En la década del 60, este proceso continuó y se amplió. A la creación de dos nuevas editoriales como ERA (1960) y Siglo XXI (1965) se le sumó la inauguración del Museo de Artes y Ciencias (1960) y de las sedes actuales del Museo Nacional de Antropología (1964) y el Museo de Arte Moderno (1964). Por el lado del cine, nuevas entidades medulares en este contexto de renovación tuvieron lugar por aquellos años. En 1959 se creó la Sección de Actividades Cinematográficas de la Universidad Nacional Autónoma de México y, en 1960, la Filmoteca de la UNAM. Al año siguiente se fundó el grupo Nuevo Cine, el cual lanzó al poco tiempo la revista homónima. Dos años más tarde se gestó el Centro Universitario de Estudios Cinematográficos (CUEC), dependiente de la UNAM. Asimismo, en 1964, el Sindicato de Trabajadores de la Producción Cinematográfica (STPC) convocó al I Concurso de Cine Experimental, en el cual participaron directores emergentes que vislumbraron un aire de cambio. Todas estas formaciones se encontraban en sintonía con las prácticas innovadoras que se estaban desarrollando en la región y por fuera de ella. Tal como señala Mariano Mestman (2016), se estableció un "fluido diálogo con los procesos de renovación y experimentación cultural sesentistas en el plano internacional [...] aunque cada país reconozca movimientos propios y esas influencias se procesen en configuraciones culturales particulares" (p. 39).

En consonancia con los objetivos de este trabajo, a continuación nos enfocaremos específicamente en el campo cinematográfico mexicano durante esta etapa, su vínculo activo con otros espacios de la cultura y el rol de la universidad para con la modernización estética y el sustento posterior brindado en torno a la politización acaecida dentro de ese ámbito. No obstante, previamente, para poder comprender estas singularidades, es necesario señalar dos premisas que deben ser leídas en un marco regional. Por un lado, entre las décadas del 30 y del 50, México, al igual que Argentina y de forma tardía Brasil, logró forjar una sólida industria cinematográfica tomando como base el modelo hollywoodense de estudios, estrellas y géneros. Luego del apoyo brindado a los aliados en la Segunda Guerra Mundial, este se benefició del abastecimiento de película

\footnotetext{
Para profundizar en esta temática, véase Driben (2012).

6 La literatura y el teatro también tuvieron un resurgimiento cultural en los 50 con exponentes como Carlos Fuentes, Juan Rulfo, Juan José Arreola, Salvador Novo y Seki Sano, entre otros.
} 
virgen por parte de los Estados Unidos. Para mediados de la década del 50, el modelo industrial en Argentina y México comenzó a sufrir un claro desgaste, mientras que Brasil tomó la delantera. De este modo, Paulo Antonio Paranaguá (2003) etiqueta a estas tres cinematografías como productivas, al tiempo que países como Chile, Cuba o Venezuela, por ejemplo, no alcanzaron a conformar en esta fase una tradición industrial estable -en cuanto a volumen y rentabilidad-, dando cuenta del carácter disímil y heterogéneo del cine latinoamericano. Por otro lado, es posible constatar que el film breve se erigió a partir de los 50, en la mayoría de los países de América Latina, como un impulsor de la renovación cinematográfica, convirtiéndose en ciertos casos en una piedra angular de la modernidad fílmica. Salvo algunas excepciones, el cortometraje - por su marginalidad, sus bajos costos y las nuevas posibilidades técnicas que arribarían poco a poco a la región- se transformó en un medio eficaz que se desenvolvió en espacios alternativos a la industria, como los talleres, los seminarios y las escuelas de cine, epicentros de la renovación.

Si bien es cierto que uno de los principales estímulos para la renovación del cine en México fue el Concurso de Cine Experimental que provino del propio ámbito de la industria, diversas propuestas innovadoras procedentes de espacios universitarios, alternativos e independientes antecedieron y acompañaron este desarrollo. Una de las más importantes fue, sin dudas, la constitución del grupo Nuevo Cine a comienzos de 1961. ${ }^{7}$ Tomando como referencia a la nouvelle vague francesa, y en concordancia con los "nuevos cines" europeos y latinoamericanos, este se propuso revertir la crisis del cine nacional y renovar la cultura cinematográfica en México (Miquel, 2010). ${ }^{8}$ Entre sus objetivos, asentados en el manifiesto del grupo publicado en el suplemento cultural "México en la cultura" del diario Novedades, se encontraba la defensa de la libertad de expresión de los cineastas, la consolidación de espacios para difundir cine independiente, documental y de cortometraje, el impulso a los cineclubes y la creación de un ámbito de formación. ${ }^{9}$ A pesar de que en su corta existencia -de enero de 1961 a agosto de 1962- no alcanzó a llevar a cabo todas las acciones deseadas, el grupo estableció el horizonte de expectativas de una nueva generación de pensadores y hacedores vinculados al cine, puesto que la mayoría de sus miembros participaron luego de los espacios surgidos al interior del terreno universitario, en el que hallaron un sustento institucional que acogió sus formas de concebir el quehacer fílmico. Del mismo modo que muchos de los movimientos y tendencias cinematográficas sesentistas, Nuevo Cine contó con una revista homónima que ofició en tanto órgano legitimador y difusor de

\footnotetext{
Estaba integrado por figuras como Luis Alcoriza, Manuel Barbachano Ponce, José de la Colina, Jomí García Ascot, Salvador Elizondo, Carlos Monsiváis y Emilio García Riera, entre otros.

8 En el balcón vacío (Jomí García Ascot, 1961) funcionó como película-manifiesto del grupo (Ramírez Miranda, 2015).

9 La voluntad por instaurar una cinemateca y la intención de profundizar en la investigación sobre el cine local marcan la perspectiva patrimonial que el grupo vislumbraba para con el cine mexicano (Wood, 2015).
} 
su línea de pensamiento. El proceso innovador que pretendía el grupo implicaba como primer paso para subsanar la crisis un fuerte embate frente al núcleo de realizadores que, a través del sindicato, regulaba la producción e impedía el ingreso a la industria de nuevas figuras. Esta presión derivaría pronto en la concreción del ya mencionado concurso. No obstante, la renovación también respondía a un contexto cultural más amplio, en el cual se intentaba canalizar la frenética modernización que el país estaba experimentando (De la Vega Alfaro, 2015). En este sentido, ese espíritu renovador era compartido por otras disciplinas artísticas como las artes plásticas, en la que un grupo de pintores, principalmente de la mano del arte abstracto, arremetió contra las formas anquilosadas del muralismo bajo el sustento de las entidades oficiales, buscando un recambio generacional. De hecho, artistas como Vicente Rojo o Gabriel Ramírez eran parte del grupo Nuevo Cine, lo cual marcó un camino común que tendría su punto culminante en el compromiso social y la radicalización política del campo cultural a finales de la década.

Por su parte, como hemos destacado anteriormente, la UNAM fue fundamental para la renovación del arte y del cine local. Uno de los primeros indicios de este nuevo panorama fue el seminario de cine que, dentro de la Universidad, coordinó Jaime García Terrés en 1954. Poco tiempo después, el cine encontraría allí un terreno propicio para su consolidación y expansión, siendo la figura de Manuel González Casanova una pieza clave en este recorrido, especialmente en torno a la problemática patrimonial que abordaremos a continuación. A comienzos de los 50, fue el impulsor de la cultura cineclubística en México, y hacia finales de la década fue convocado por la Dirección General de Difusión Cultural de la UNAM para desarrollar el área destinada al séptimo arte, dando forma en 1959 a la Sección de Actividades Cinematográficas (transformada en Departamento a mediados de los 60 y en Dirección general durante los 80). A lo largo de sus veinte años en el cargo, produjo más de treinta cortometrajes y casi una decena de largometrajes. En 1963, luego de promover varios cursos y talleres, fundó el Centro Universitario de Estudios Cinematográficos (CUEC), con el objetivo de formar profesionales e incentivar la realización de un cine moderno alejado de los imperativos industriales. Ese mismo año, el Centro inició una cuantiosa producción de cortometrajes cuyo puntapié inicial fue, en calidad de ejercicio práctico, $A$ la salida (Giancarlo Zagni, 1963). Durante su gestión (1963-1978), el CUEC produjo alrededor de 120 films breves y varios largometrajes. Cineastas como Jaime Humberto Hermosillo, Alfredo Joskowicz y Leobardo López Arretche, referentes de un cine renovador, fueron egresados y docentes del CUEC. Sin embargo, el valor de su tarea no solo radicó en el estímulo a la producción y la consagración de nuevos espacios que sustentaban la tan ansiada renovación. Como bien señala Gabriel Rodríguez Álvarez (2009), “Manuel González Casanova ha dedicado su vida al cine, entendiéndolo como una cultura en movimiento 
Javier Cossalter

¿Arte?, ¿documento?, ¿política? La construcción de memoria en el cortometraje alrededor del 68 mexicano

y un patrimonio que es posible conocer, difundir y resguardar" (p. 15). En este sentido, uno de sus mayores aportes fue la creación, como parte de la sección que presidía, de la Filmoteca de la UNAM en 1960. Desde entonces, esta entidad asumió la labor de rescatar, recuperar, preservar y, por sobre todas las cosas, dar acceso y difusión al patrimonio cinematográfico mexicano. Para 1963, su acervo llegaba a los 137 films y, cuatro años más tarde, disponía ya de 300 obras. Asimismo, González Casanova se encargó de divulgar y dar a conocer los films por medio de la organización de festivales, encuentros en cineclubes y programas de televisión.

Resulta pertinente señalar que en los espacios de producción recién mencionados predominó el cortometraje documental por sobre las demás tipologías fílmicas. La escasez de recursos económicos podría ser un factor que justifique esta situación, ${ }^{10}$ aunque el carácter patrimonial y de documentación que comenzaba a otorgársele al medio cinematográfico quizás determinó la productividad de este, lectura retrospectiva que debe contemplar necesariamente la actividad cinematográfica alrededor del 68 mexicano.

Ahora bien, la Universidad fue además un lugar de encuentro entre las esferas artísticas no solo en términos estéticos, sino, por sobre todas las cosas, en cuanto a su vertiente política. La presencia de Manuel González Casanova resulta medular para comprender la injerencia del cine mexicano universitario en estas dos facetas. En primer lugar, esta entidad promovió el acercamiento entre el cine y las artes visuales a través del fomento y el financiamiento de cortometrajes en torno a la corriente del film sobre arte, destacándose aquellas obras alrededor de la Generación de la ruptura. Por ejemplo, el propio González Casanova realizó Tamayo en 1967. Aunque en este punto sobresale la trilogía denominada La creación artística (Juan José Gurrola, 1965), sobre las figuras de José Luis Cuevas, Alberto Gironalla y Vicente Rojo; "serie que marca un claro enfoque político de la UNAM al conceder un espacio considerable a los artistas de la ruptura" (Cossalter, 2018, p. 26), artistas que compartían con los cineastas emergentes un clima de época y una necesidad por experimentar con el lenguaje. En estos films es posible advertir una nítida perspectiva intermedial gracias al registro y a la intervención del proceso creativo y de las obras plásticas mediante recursos fílmicos innovadores. Esta intermedialidad, concebida en tanto fenómeno que configura un cruce de fronteras entre medios de distinta naturaleza (Rajewsky, 2005), se vislumbra en estos cortometrajes a través del procedimiento de la dramatización y narrativización de las obras pictóricas, así como de la presencia performática y activa del artista en escena.

\footnotetext{
${ }^{10}$ Otro factor de relevancia podría ser la necesidad de ampliar la programación de la televisión emergente y, para ello, la participación universitaria era medular.
} 


\section{Austral Comunicación \\ Volumen 10, número 1 (junio de 2021): 183-206 ISSN (I) 2313-9129. ISSN (E) 2313-9137}

Asimismo, por fuera de esta tendencia puntual, fueron concebidos otros films breves acerca de las artes visuales. Entre ellos, mencionamos José Guadalupe Posada (1966) y Siqueiros (1969), ambos de Manuel González Casanova, Remedios Varo (1965) de Jomí García Ascot y Arte Barroco (1968) de Juan Guerrero y Carlos González Morantes. Por último, Felipe Cazals también fue un cineasta moderno que abordó en su producción temprana esta disciplina.

Podemos afirmar que la Universidad, desde la Dirección General de Difusión Cultural y el CUEC, apoyó y respaldó plenamente al movimiento estudiantil en su lucha, brindando los recursos materiales para que los estudiantes y los profesores salieran a las calles a filmar. Hay que resaltar que recién para 1968 el CUEC dispuso de un equipamiento considerable para ofrecer una formación práctica deseable, aunque decidió destinar todo su capital para registrar los acontecimientos acaecidos (Rodríguez Álvarez, 2009). Prácticamente todas las escuelas de cine en América Latina modificaron, hacia finales de los 60 , sus planes de estudio a favor del compromiso social y la acción política, entendiendo al cine como un vehículo de transformación. El mismo González Casanova incentivaba a los estudiantes a comprometerse desde el quehacer cinematográfico con la realidad circundante. Su determinación política y su concepción patrimonial lo llevaron a realizar el film inconcluso Los estudiantes, la Universidad y la violencia (1968) y a ser el principal promotor del primer largometraje universitario: El grito.

Para concluir, el respaldo al movimiento estudiantil partía de la Universidad, pero la excedía, abrazando a un sector del campo cultural de manera mancomunada. Artistas, literatos e intelectuales de diversa índole colaboraron con el movimiento por medio de pronunciamientos y acciones artísticas concretas. ${ }^{11}$ Este es el caso de la performance Mural efímero, registrada en el cortometraje homónimo (Raúl Kamffer, 1968-1973), el cual significó uno de los puntos más altos de la contracultura, del encuentro entre cineastas y artistas plásticos y de la voluntad por construir una memoria audiovisual en torno a un presente histórico convulsionado.

Como coda de este apartado, resulta pertinente señalar que el cine moderno y el cine político continuaron y terminaron de consolidar su desarrollo en México durante los 70, después del cimbronazo que significó el fenómeno alrededor del movimiento estudiantil. A fines de los 60, Arturo Ripstein, Felipe Cazals, Rafael Castanedo, Pedro Miret y Tomás Pérez Turret formaron el grupo Cine Independiente de México, sin apoyo estatal, dentro del cual concibieron varias películas rupturistas. Por otro lado, en 1971 se creó el Centro de Producción de Cortometraje (CPC), que si bien contaba con

\footnotetext{
${ }^{11}$ Hacia fines de 1968, un grupo de artistas decidió romper con el Instituto Nacional de Bellas Artes y con el Comité Organizador de los Juegos de la XIX Olimpiada -en respuesta a la represión propiciada por el Gobierno-, y organizó la muestra conocida como Salón Independiente.
} 
Javier Cossalter

¿Arte?, ¿documento?, ¿política? La construcción de memoria en el cortometraje alrededor del 68 mexicano

fondos públicos y estaba destinado a difundir -entre otras cosas- obras gubernamentales, también impulsó la realización de films de carácter social y artístico. Finalmente, hacia mediados de los 70, un grupo de estudiantes fundó el Taller de Cine Octubre, con el objetivo de producir un cine al servicio de la lucha de los trabajadores. Todos estos espacios tuvieron un factor en común: la presencia del film breve como medio de experimentación y vehículo de transformación social.

\section{El corto documental en torno al 68 mexicano. Cine, dispositivo y documento}

Como ya hemos subrayado, es posible referirse a esta etapa histórica a nivel regional desde la conceptualización de una época, caracterizada por la modernización y la creciente politización del campo cultural en países atravesados por revueltas sociales al interior de contextos signados por golpes de Estado y Gobiernos autoritarios. En esta senda, Mariano Mestman (2016) profundiza en estos aspectos centrales y plantea dos postulados para comprender el devenir sociocultural de América Latina: lo contracultural y el tercermundismo. Por tanto, el autor propone pensar a la región

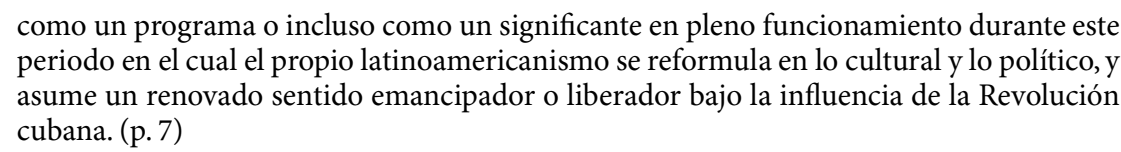

Dentro de este panorama, el arte -y, en este caso concreto, el cine- jugó un papel destacado en tanto dispositivo de aprehensión y transformación social. Si bien los objetivos de orden político pasaron a un primer plano, ciertos elementos estéticos/ formales innovadores contribuyeron con el anhelo contracultural.

Ahora bien, la capacidad del cine para registrar en imágenes un acontecimiento histórico refuerza y potencia sus posibilidades de acción. Tal como sostiene Pierre Sorlin (2008), "el cine no es sólo el reflejo de su época, pertenece a ella y creando figuras, fenómenos, modos de ser, ejerce acción en ella” (p. 26). Esta conjunción de funcionalidades puede observarse nítidamente en el quehacer cinematográfico alrededor del 68 mexicano, aunque -a diferencia del cine político-militante surgido en otros países de la región- en México el resguardo del orden constitucional fue una premisa consensuada por el movimiento estudiantil (Vázquez Mantecón, 2018). La crítica al Gobierno giraba en torno al desvío de los carriles de legalidad del Estado. Mientras que films como La hora de los hornos (Cine Liberación, 1966-1968), Me gustan los estudiantes (Mario Handler, 1968) o Argentina, Mayo de 1969: los caminos de la liberación (Realizadores de Mayo, 1969) convocaban al pueblo a la lucha armada, en las películas producidas por el movimiento estudiantil mexicano la contrainformación y la concientización fueron 


\section{Austral Comunicación \\ Volumen 10, número 1 (junio de 2021): 183-206 ISSN (I) 2313-9129. ISSN (E) 2313-9137}

los pilares para alcanzar un mayor compromiso en miras al añorado cambio, así como el punto de partida hacia la construcción de una memoria visual.

El conflicto estudiantil que dio origen al movimiento surgió en el contexto de un país en plena organización de los Juegos de la XIX Olimpíada. Conflicto que, según las fuentes, comenzó en julio con un enfrentamiento entre estudiantes de dos instituciones (reprimido por la policía) y fue escalando en términos de organización, movilización y violencia estatal. La represión de la manifestación del 26 de julio derivó en la toma de las escuelas por parte de los estudiantes y en un nuevo ataque del ejército, esta vez a la Preparatoria 1 de la UNAM. Este hecho marcó un antes y un después, determinando el pronunciamiento de las autoridades universitarias y la consiguiente organización del Consejo Nacional de Huelga $(\mathrm{CNH})$, un ente democrático que, a través de asambleas, decidiría el accionar del movimiento y cuyo acto fundacional fue la entrega a las autoridades nacionales de un petitorio con las seis principales demandas estudiantiles frente a los actos represivos. Durante el mes de agosto, el movimiento se consolidó y organizó dos grandes manifestaciones, dispersadas por los militares. Luego de la amenaza del presidente Gustavo Díaz Ordaz al movimiento y la posterior Marcha del Silencio, se produjo la toma de la Ciudad Universitaria por parte del ejército y el apresamiento de estudiantes y profesores. La manifestación de octubre en la Plaza de las Tres Culturas fue el punto crítico: el ejército sitió la plaza y abrió fuego contra los estudiantes, dando lugar a la denominada Masacre de Tlatelolco, que desembocó en el final del movimiento estudiantil. Como bien señala Álvaro Vázquez Mantecón (2016), "el conflicto entre el Gobierno y los estudiantes puso al descubierto el autoritarismo de un régimen que se negaba a reconocer las demandas de libertad política de una clase media que había crecido al amparo del desarrollismo de los años sesenta" (p. 289). De cara a esta situación, y con vistas a romper el cerco informativo oficial, la Universidad se propuso registrar el conflicto desde los inicios y conformar un cine-documento, inmediato y políticamente activo. ${ }^{12}$

El primer documental en relación con el movimiento estudiantil fue Únete pueblo (Óscar Menéndez, 1968), que registra el desarrollo de este desde el interior entre el 26 de julio y el 27 de agosto, financiado por el Consejo Nacional de Huelga y con la colaboración de varias personas vinculadas a la Universidad. Posteriormente, con material fílmico y fotográfico en torno a esos acontecimientos, Menéndez realizaría dos documentales más sobre el tema: Dos de octubre, aquí México (1968-1970) e Historia de un documento (1970-1971). Sin embargo, de acuerdo con lo expresado por Juncia Avilés Cavasola (2015), "los estudiantes consideraban necesario ir más allá del acto informativo del cine de propaganda. No solo querían dejar una huella de lo que ocurría,

${ }_{12}$ Para revisar en detalle los hechos acaecidos alrededor del conflicto/movimiento estudiantil y la extensa filmografía concebida al respecto, véase Avilés Cavasola (2015). 
Javier Cossalter

¿Arte?, ¿documento?, ¿política? La construcción de memoria en el cortometraje alrededor del 68 mexicano

sino invitar a diversos sectores de la sociedad a que participaran de ella" (p. 65). En este sentido, y de la mano de las brigadas informativas del CUEC, un grupo de cineastas -entre los que se encontraban Paul Leduc y Rafael Castanedo- se acercaron al CNH para realizar cortometrajes documentales testimoniales que presentaran el punto de vista del movimiento estudiantil. De este modo, surgieron los cuatro Comunicados cinematográficos del Consejo Nacional de Huelga, de autoría colectiva, de los cuales se conservan tres, y que, a diferencia de lo que comúnmente se dice de estos, combinan la noción de un documento vivo con un marcado sentido estético que se sostiene, de un modo similar a los cortos realizados por el cubano Santiago Álvarez, mediante el uso evidente del montaje y la articulación creativa entre las bandas de imagen y sonido.

En parte, esta semejanza con la obra del documentalista cubano deviene de la predominancia de imágenes fotográficas por sobre imágenes fílmicas que evidencian los comunicados y la potencia que adquiere el montaje en la construcción de una narración política y poética.

El comunicado $n^{\circ}$ 1, "La agresión", está conformado por fotografías extraídas de la revista ¿Por qué?, recortes periodísticos y una banda sonora experimental que, junto con la edición, le agregan al objetivo comunicacional inmediato -la mostración de las causas de la protesta- un marco estético. Según lo expresado por Álvaro Vázquez Mantecón (2018), "se trata de un lenguaje cinematográfico cercano a la vanguardia" (p. 79). En este sentido, el carácter contracultural tensiona los polos de arte y documento. El montaje, en compañía del encuadre y los movimientos de cámara, edifica una secuencia narrativa a partir de las fotos fijas, imprimiéndoles dinámica y movimiento. La banda de sonido refuerza este aspecto, por ejemplo, al añadir un sonido similar al de un grito junto a la imagen fija de un estudiante que efectivamente grita. A su vez, con el propósito de contrainformar, se incorporan de forma crítica recortes periodísticos de una prensa oficial que respalda el accionar gubernamental, al tiempo que -en la banda sonora- la música electrónica a modo de ruidos disonantes marca una tensión en aumento. Finalmente, el primer comunicado concluye con el registro cinematográfico de una las manifestaciones -la del 1 de agosto- y de las diversas pancartas en alto, un motivo visual que se repetirá en la mayoría de los films en torno al movimiento estudiantil y que deja entrever su dimensión contracultural.

El comunicado $n^{\circ} 2$, "La respuesta", comienza con una secuencia de tres fotografías y una toma aérea que exhiben la organización y rápida concentración de los estudiantes en la manifestación del 13 de agosto, mientras que en la banda sonora oímos una versión de la canción de Violeta Parra "Me gustan los estudiantes", cuya letra describe de manera lúcida la coyuntura mexicana y realza el espíritu colectivo de lucha. Acto seguido, podemos observar un fragmento audiovisual de la asamblea del $\mathrm{CNH}$ en la que se resuelve el cese de las actividades en línea con la exigencia del cumplimiento 


\section{Austral Comunicación \\ Volumen 10, número 1 (junio de 2021): 183-206 ISSN (I) 2313-9129. ISSN (E) 2313-9137}

del pliego. Luego, los registros de la manifestación pasan a un primer plano a través de diversos recursos formales. En primer lugar, de forma simbólica, se interviene la película mediante el rayado de esta sobre una fotografía, encima del rostro de uno de los manifestantes que porta un megáfono, en alusión al cerco informativo que intentaban quebrar. En segundo lugar, nuevamente, la banda sonora -dos discursos y la canción de Judith Reyes "Los granaderos"- funciona como complemento al montaje de fotos fijas -que incluye movimientos de cámara y el procedimiento del zoom-, colaborando en la creación de una temporalidad cinematográfica sobre la base de una narración que pone el acento en la concientización y la contrainformación. Este bloque de imágenes focaliza también en las pancartas, carteles, graffittis, serigrafías y volantes desplegados en la manifestación, en la que el punto más álgido está representado -registrado cinematográficamente- por una suerte de performance simbólica en la cual se quema el muñeco de un gorila granadero. Una vez más se puede apreciar cómo el talante contracultural trasciende al mero panfleto, y no por casualidad el cortometraje documenta con agudeza ese ánimo. Por último, este segundo comunicado acaba con un texto en letra negra sobre fondo blanco, escrito a máquina y a la manera de un intertítulo propio del cine político de la época, en el que se evidencia que la lucha estudiantil se convirtió en una lucha popular.

Para concluir, el comunicado $\mathrm{n}^{\circ} 4$ está centrado en la manifestación del 27 de agosto y la represión del día siguiente. No obstante, este se inicia con un procedimiento novedoso, hasta ahora ausente, que remite de algún modo a la corriente del cinéma vérité francés: el testimonio de la gente ante las preguntas de los estudiantes acerca del apoyo al movimiento estudiantil escoltado por una cámara que contempla la modernidad de la ciudad. Posteriormente, se retoman las formas creativas de articular las bandas de imagen y sonido para desarrollar la línea documental de acción y generar conciencia: un discurso que acompaña a los créditos del comunicado; imágenes del encuentro cultural, pinturas y pancartas junto a las consignas y los cánticos de los estudiantes; fotografías fijas fuera de foco de los policías al ritmo del sonido del latir de un corazón. Este latir continúa durante las imágenes en movimiento que dan cierre al comunicado, en el que visualizamos desde una toma aérea las corridas de los manifestantes y la represión policial, la cual es señalada de forma redundante por una suerte de dedo acusador delante de la cámara.

En resumen, los tres comunicados resaltan la condición del cine como agente de la historia (Ferro, 1980). Es decir, pretenden influir en la sociedad e intervenir en ella generando algún tipo de respuesta. Para ello, los estudiantes de cine "aprendieron la importancia de lo inmediato -por otra parte, esencia del documental- al hacer tomas oportunas" (Vázquez Mantecón, 2016, p. 295). La preocupación por la inmediatez, la escasez de los recursos y la falta de experiencia determinó la imperfección del mate- 
Javier Cossalter

¿Arte?, ¿documento?, ¿política? La construcción de memoria en el cortometraje alrededor del 68 mexicano

rial registrado. En este sentido, el mero registro fotográfico o fílmico de los hechos no constituye por sí solo al documento (audio)visual en una obra de carácter estético. Son el sentido contracultural provisto y el lenguaje moderno utilizado en la construcción final los elementos que dotan a la propuesta comunicacional política de un halo artístico, cuando menos estético. ${ }^{13}$

A diferencia de los Comunicados... y del mencionado corto de Óscar Menéndez, ${ }^{14}$ hubo otras dos producciones que, filmadas igualmente en pleno desarrollo del movimiento estudiantil, fueron terminadas unos pocos años después. Se trata del largometraje El grito (Leobardo López Arretche, 1968-1970), concebido por el CUEC, y el film breve Mural efímero (Raúl Kamffer, 1968-1973), solicitado por la Dirección General de Difusión Cultural de la UNAM. En este punto surge el interrogante de si es posible considerarlas como obras que abordan el presente histórico. Desde el plano de la conformación de un documento visual, no hay dudas. Desde la óptica de la práctica política de intervención de la realidad inmediata, tampoco, aunque vale la pena realizar una breve reflexión al respecto.

Ambos proyectos surgieron durante el transcurso de los acontecimientos, por lo que su intención era influir en la sociedad por medio de la contrainformación y la concientización. Si entendemos al presente en tanto un proceso continuo y no como un mero corte sincrónico, podemos pensar que, debido a la magnitud del fenómeno, tales objetivos estaban todavía vigentes en el contexto de culminación de estos films. Ahora bien, es cierto que estas dos películas plantean una relectura de los hechos (Avilés Cavasola, 2015; Vázquez Mantecón, 2018), pero lo hacen anclados en un presente cercano a estos, o, mejor dicho, en un pasado próximo (Lara López, 2005), y el material registrado sigue siendo el núcleo sobre el que se fundan las obras. En definitiva, podrían ser tratadas como productos híbridos en cuanto a su condición de pasado/presente, aunque para los fines de nuestro trabajo constituyen inequívocamente un patrimonio del presente (Colin, 2014).

En esta oportunidad, analizaremos únicamente Mural efímero, ya que nos hemos enfocado solo en el cortometraje alrededor del movimiento estudiantil. Asimismo, El grito es un film que ha sido harto trabajado por el campo académico, si bien no por ello resulta menos importante su estudio. ${ }^{15}$ Junto con las dos obras examinadas en el presente apartado, este largometraje configura la tríada que dio el puntapié inicial para

\footnotetext{
${ }_{13}$ Es importante señalar que estos comunicados fueron enviados al Festival de Mérida en 1968 y se presentaron de forma conjunta bajo el título Testimonios de una agresión.

14 Dentro de este corpus podríamos ubicar también al cortometraje de Manuel González Casanova Los estudiantes, la Universidad y la violencia (1968), aunque resultó inconcluso.

15 Es importante destacar que la propuesta inicial era realizar con esas imágenes una serie de cortometrajes, lo que marca la eficacia del film breve en contextos de urgencia social. La organización final del largometraje en cuatro bloques da cuenta de ello. Para profundizar en el análisis del film y su puesta en valor, véanse Mestman (2014) y Ferrer Andrade et al. (2018).
} 


\section{Austral Comunicación \\ Volumen 10, número 1 (junio de 2021): 183-206 ISSN (I) 2313-9129. ISSN (E) 2313-9137}

la formulación de una memoria visual en torno al 68 mexicano. Las tres comparten varias de las imágenes que se convertirían en motivos visuales recurrentes en relación con el fenómeno histórico referido.

En Mural efímero, las facetas de arte y documento se vislumbran con mayor nitidez, puesto que el corto registra el proceso de construcción y desarrollo de la performance homónima y del evento contracultural que la contiene. La intención de recoger en imágenes un acontecimiento artístico y político, fugaz y transitorio, da cuenta del compromiso que la instancia de producción tenía en torno a la elaboración de una memoria visual de un suceso concebido como trascedente para la historia del país. A su vez, de acuerdo con lo señalado, este hito y su filmación constatan uno de los estadios más altos de comunión entre las diferentes disciplinas y agentes del campo cultural, a través del encuentro del arte visual, el cine, la universidad y la determinación política.

Como reacción y solidaridad ante la violencia represiva que padecía el movimiento estudiantil por parte del Estado, un grupo de alrededor de cincuenta artistas plásticos -entre los que se hallaban José Luis Cuevas, Ricardo Ochoa, Manuel Felguérez y Luis Urías- resolvió levantar un mural sobre las láminas acanaladas que protegían a una ya damnificada estatua de Miguel Alemán, situada en la explanada de la Ciudad Universitaria. Este acto performático se llevó a cabo en el marco de uno de los festivales culturales organizados por el $\mathrm{CNH}$. En concreto, se trató de una creación colectiva, ejecutada con fondos de donativos personales, en la que artistas de distintas procedencias y estilos se congregaron con un único propósito: apoyar al movimiento estudiantil y visibilizar la conducta autoritaria del presidente Gustavo Díaz Ordaz por medio de una intervención artística comprometida. El grueso del film, de tan solo diez minutos de duración y realizado en color, consiste en un registro con enfoque observacional en torno al desarrollo del hecho artístico, acompañado de un montaje dinámico que presenta diversos emplazamientos de cámara, los cuales evidencian múltiples puntos de vista en torno al mural. Por su parte, la cámara no solo se aboca al seguimiento del fenómeno en sí mismo y del producto culminado a través de un recorrido que se concentra en los distintos sectores de la obra, sino que también repara, con una óptica similar, en el festival que aúna al artefacto estético y que abarca la emisión de discursos y la lectura de textos poéticos, la presencia de mesas populares de libros y bandas musicales en vivo.

No obstante, según lo anticipado, el cortometraje manifiesta una doble temporalidad: la de gestación del proyecto y toma de imágenes y la del montaje final. Mientras que el registro observacional de creación del mural expone la voluntad y necesidad de documentar el evento para difundir el compromiso de la esfera cultural con el movimiento estudiantil, la etapa de posproducción -diferida en el tiempo, luego de acaecida la Masacre de Tlatelolco- aporta una nueva lectura, la cual refuerza el carácter 
Javier Cossalter

¿Arte?, ¿documento?, ¿política? La construcción de memoria en el cortometraje alrededor del 68 mexicano

de contrainformación y concientización del film, postura análoga a la revisada en los Comunicados..., concluidos y divulgados en pleno desarrollo de los hechos.

Tres recursos colaboran en este cometido: la incorporación en la banda sonora del tema musical de Deep Purple "Child in time", que "acentúa el tono contracultural de las imágenes” (Vázquez Mantecón, 2018, p. 81); la presencia de textos poéticos proferidos por una voz en over, que potencian la perspectiva política del sujeto de enunciación; ${ }^{16}$ y un collage experimental final de fotografías superpuestas de los jóvenes muertos en la Plaza de las Tres Culturas y de uno de los principales responsables de la masacre (el general y jefe del Departamento del Distrito Federal, Alfonso Corona del Rosal). En tal sentido, podemos reafirmar que el cortometraje, a pesar de elaborar parcialmente una reflexión en retrospectiva, mantiene activos los objetivos iniciales de quebrar el cerco informativo y concientizar a la sociedad, en un presente que se piensa como un puente directo con la coyuntura abordada, de la mano de una instancia de producción que ofrece claros indicios de un afán por sentar las bases para edificar una memoria visual sobre lo ocurrido.

\section{La puesta en valor patrimonial de la imagen fílmica, vehículo promotor de memoria audiovisual}

Si bien el consenso mundial y la plena conciencia sobre la existencia de un patrimonio audiovisual que debe ser conservado data de comienzos de la década del 80 , a partir de la Recomendación sobre la Salvaguardia y la Conservación de las Imágenes en Movimiento (1980) de la UNESCO, la importancia del cine en cuanto a su valor cultural es un asunto que comenzó a discutirse desde los mismos inicios del cinematógrafo. Oskar Messter, fabricante alemán de cámaras fotográficas, decía en 1898 que "gracias al cine los hechos históricos dejarán una huella en el porvenir, se podrá reproducirlos naturalmente, no solo en su época, sino también para la generaciones futuras" (Messter como se cita en Sorlin, 2008, p. 19). En la década del 30 comenzaron a fundarse las primeras cinematecas y archivos fílmicos. Ahora bien, la voluntad institucional/individual por conservar algo denominado patrimonio fílmico no es lo mismo que el afán de adjudicación patrimonial -o, mejor dicho, anticipación patrimonial (Colin, 2014)- de un film en la instancia de producción. De hecho, no siempre van de la mano ambas determinaciones. En este sentido, Manuel González Casanova fue una figura que entendió al cine como un patrimonio en estas dos facetas. No solo fundó la Filmoteca de la UNAM para resguardar y preservar el acervo mexicano, ${ }^{17}$ sino que impulsó el

\footnotetext{
${ }_{16}$ Dos frases pronunciadas ilustran particularmente el ánimo dispuesto: "Quisimos hacer hablar los muros, llenar el silencio" y "La juventud combatió, se enterró sin flores y aun muerta fue violada".

${ }^{17}$ En esta misma línea hay que subrayar que fue el propio González Casanova que en el año 1965, durante el Festival Internacional de Cine de Mar del Plata, promovió la creación de la Unión de Cinematecas de América Latina (UCAL), una organización regional capaz de congregar a todos los archivos latinoamericanos afines al séptimo arte.
} 


\section{Austral Comunicación \\ Volumen 10, número 1 (junio de 2021): 183-206 ISSN (I) 2313-9129. ISSN (E) 2313-9137}

desarrollo de un cine consciente de su función social y cultural en dos vertientes: la corriente del film sobre arte y la tendencia de registro y documentación del movimiento estudiantil.

Por lo dicho hasta el momento, podemos sostener que la noción de patrimonio, comprendida desde la perspectiva de una construcción social y cultural, no comporta de forma excluyente y obligatoria una relación con el pasado. Así pues, estamos en condiciones de afirmar que los cortometrajes documentales analizados en el apartado anterior se concibieron en tanto patrimonio del presente, es decir, como "un objeto que no tiene fundación y legitimidad histórica para transformarse oficialmente en patrimonio" (Colin, 2014, p. 6), pero al cual se le otorga un estatuto patrimonial. A finales de los 60, la UNAM en su totalidad entendió al cine como una herramienta de transformación social y como un medio capaz de documentar un hecho sociocultural trascedente susceptible de convertirse en un patrimonio (audio)visual en torno a los acontecimientos. De esta forma, podemos aseverar que aquellos primeros cortos documentales alrededor del 68 mexicano forjaron una memoria del presente. $\mathrm{Al}$ igual que la idea de patrimonio, el concepto de memoria no necesariamente debe asociarse con el tiempo pasado. La memoria, pensada en tanto proceso antes que producto, puede ser comprendida como trabajo (Jelin, 2002), puesto que se manifiesta a la manera de una actividad de creación y construcción. El cine, de acuerdo con sus cualidades de registro visual y sonoro, se erige como un dispositivo efectivo de producción de memoria(s). A propósito de la relación entre el cine, la memoria y el eje temporal, Carmen Guarini (2002) expresa:

\footnotetext{
la acción misma de registrar elementos de un presente forman parte del trabajo de construcción de la memoria social, ya que la elaboración de registros audiovisuales no es un acto mecánico sino una empresa llevada adelante por sujetos sociales históricos que inciden subjetivamente en su producción. (p. 116)
}

Precisamente por tal motivo, hemos hecho hincapié en el análisis de la doble condición de arte/documento que vislumbran los cortos en torno al movimiento estudiantil, ya que no son meros registros inocuos, sino que su función comunicacional -y mnemónica-, además de enmarcarse en un halo estético, está orientada desde un enfoque subjetivo, anclado en un presente de convulsión social colectiva.

Tanto los Comunicados... como Mural efímero -y, por supuesto, el largometraje El grito, sobre el cual hemos señalado su valor testimonial y su productividad en la posterior tradición visual sobre lo acaecido- dan cuenta de algunos elementos que colaboraron en la edificación y consolidación de una memoria dinámica acerca del movimiento estudiantil. En primer lugar, la función contrainformativa propuesta por estos cortos conlleva en sí misma un anhelo por dar forma a una memoria activa so- 
Javier Cossalter

¿Arte?, ¿documento?, ¿política? La construcción de memoria en el cortometraje alrededor del 68 mexicano

bre lo acaecido, puesto que uno de los objetivos centrales consistía en romper el cerco informativo impuesto desde el Gobierno.

En efecto, durante varias décadas, estas películas se erigieron como los únicos testimonios visuales sobre el tema (Vázquez Mantecón, 2018), de allí su fructífero carácter mnemónico. En segunda instancia, la capacidad y disposición observacional de la cámara en estos relatos contribuye al desarrollo de una memoria visual. Por fuera del montaje de fotografías fijas -en el que la cámara también tiene un papel de visibilización- el aparato de filmación se convierte en un personaje más que se involucra en la multitud para registrar en detalle, a través de un enfoque inmanente, las sensaciones experimentadas y los hechos ocurridos.

En estrecha relación con lo anterior, resulta pertinente destacar la preeminencia de una narración de lo visual como eje rector de los films por sobre un comentario verbal exterior. En los Comunicados..., la ausencia de una voz en over que oficie de guía y la utilización creativa de la banda sonora a través de los discursos y las consignas le conceden a la banda visual una posición preponderante, que se traduce en la centralidad de las fotografías fijas y el foco puesto en las pancartas y otros símbolos visuales explorados anteriormente.

Por otra parte, con respecto a Mural efímero, la intención de fijar e inmortalizar en imágenes un evento pensado como pasajero y transitorio guarda en sí un gesto consciente de adjudicación patrimonial y un deseo por conformar una memoria visual de este acto cultural para la posteridad. Por cierto, este cortometraje fue filmado en película a color, algo inusual en aquellos tiempos para una producción de bajo presupuesto realizada en condiciones de relativa urgencia; dato que trasciende la mera anécdota debido a que el registro del color es una variable fundamental a la hora de documentar de manera fidedigna los trazos del mural pictórico. En consecuencia, de acuerdo con lo expresado, estas obras elaboraron una memoria del presente y podrían pasar a formar parte de una tendencia cinematográfica particular dado que, en palabras de José Luis Sánchez Noriega (2008), "el cine de la memoria trata conflictos contemporáneos de gran trascendencia $-\mathrm{y}$, por tanto, destinados a ocupar un lugar en la historia futura-" (p. 91).

Según Peter Burke (2005), toda imagen se puede convertir en un documento histórico si se la apropia no como fuente, sino en tanto vestigio del pasado en el presente, es decir, como testimonio. De este modo, las imágenes condensan en sí mismas su propio contexto social y es desde el presente que puede estimularse y activarse su potencia como documento. En este sentido, las obras analizadas en torno al movimiento estudiantil alentaron el desarrollo de una tradición visual que, de forma muy temprana y hasta nuestros días, procuró revalorizar ese patrimonio cultural inaugural y recuperar en cada contexto particular su condición de documento histórico. Como bien señala 


\section{Austral Comunicación \\ Volumen 10, número 1 (junio de 2021): 183-206 ISSN (I) 2313-9129. ISSN (E) 2313-9137}

Álvaro Vázquez Mantecón (2018): “En su conjunto, las películas producidas sobre y por el movimiento estudiantil mexicano de 1968 se han integrado en una memoria visual contemporánea de aquel momento histórico" (p. 83); memoria visual puesta en marcha en el presente de su concepción por los cortos documentales examinados.

Estas obras primigenias no solo aportaron las imágenes que configuraron los motivos visuales más pregnantes sobre este momento histórico, sino que posibilitaron conformar un imaginario alrededor del fenómeno social y cultural, también rescatado y aludido de forma inmediata tanto en películas documentales como de ficción. No es la intención de este trabajo detallar la extensa producción cinematográfica mexicana pos-68 referida al movimiento estudiantil, tarea que con buen tino llevaron adelante, entre otros, autores como Juncia Avilés Cavasola (2015) y Rafael Aviña (2018). Sí vale la pena señalar que se trata -en presente, porque es una tendencia con inicio, pero sin final- de una producción heterogénea que abarca cortos, medios y largometrajes, diversos formatos, financiamiento independiente y de corte estatal/industrial, diferentes tipologías fílmicas y un alcance que trasciende en la contemporaneidad el ámbito estrictamente cinematográfico para abrazar el audiovisual en términos generales.

Resulta imposible reproducir en tan solo unas líneas la variedad temática y estilística abordada por estos films, lo que da cuenta de cómo cada contexto de enunciación reactiva se apropia y reelabora ese imaginario fundado en aquellas obras originarias según las coyunturas particulares y las necesidades epocales. Por ejemplo, Avilés Cavasola (2015) plantea una serie de corpus en función de determinadas variables estructurales y temporales: referencias dentro del cine universitario, un cine alegórico independiente y un cine estatal en torno al 68 durante la década del 70; un punto de vista asfixiante sobre la problemática dentro de la escasez de producciones en la década del 80 y parte de los 90; la revalorización del movimiento estudiantil de la mano del partido de izquierda en los primeros 2000. Asimismo, podemos resaltar que en los años en los que se conmemora un aniversario redondo sobre la Masacre de Tlatelolco, la producción cinematográfica al respecto, así como las actividades de rescate de la memoria visual y la revalorización de ese patrimonio, cobran gran protagonismo. ${ }^{18} \mathrm{En}$ ese sentido, el devenir del cine en torno al movimiento estudiantil refuerza el carácter mnemónico de los primeros cortos documentales aquí analizados.

Para finalizar, mencionamos un caso particular con el propósito de asentar estas premisas. Trazos en trozos: Mural efímero, México 68 (María Judith Alanís Figueroa, 2008) es un mediometraje documental ganador de la Segunda Convocatoria de Apoyo a Productores Independientes del Canal 22 de México. El film recupera la experiencia de aquel acto performático por medio de testimonios y material de archivo. La estructura del relato es más bien clásica, con algunas marcas estéticas creativas, tintes

${ }_{18}$ En 2018, a cincuenta años de los hechos, la UNAM editó una copia restaurada de El grito. 
Javier Cossalter

¿Arte?, ¿documento?, ¿política? La construcción de memoria en el cortometraje alrededor del 68 mexicano

poéticos y un claro afán de puesta en valor patrimonial. El documental está organizado a partir de bloques -de acuerdo con su origen televisivo- separados por títulos tales como "contra la máquina de guerra", "el pincel contra la imbecilidad humana", "trazos de poesía sobre láminas acanaladas", "la bitácora de un viaje in situ" y "la lucha sigue..., los cuales resumen bajo cierto lirismo los tópicos abordados en cada parte. Los testimonios, recogidos en la contemporaneidad, pertenecen a historiadores del arte, periodistas, artistas plásticos que participaron en el mural y cineastas de la época, quienes reflexionan de forma vinculada acerca de las experiencias vividas y el contexto político-cultural en el que estas se inscribieron.

Es importante subrayar dos aspectos puntuales en relación con la presentación de estas intervenciones que aluden directamente al imaginario sobre el movimiento estudiantil. Por un lado, mientras que la mayoría de los artistas y cineastas son entrevistados en sus talleres u hogares, los historiadores profieren sus palabras en un andamio ubicado en la Ciudad Universitaria, el cual funciona en tanto objeto simbólico que remite a la estructura de sustento del mural. Por otro lado, todas estas expresiones orales están enmarcadas cual obra pictórica, y el rótulo con el nombre de cada uno está apuntado en un diseño que emula una lámina acanalada, otra referencia visual y simbólica en torno al fenómeno recobrado en el film.

Ahora bien, estos testimonios se articulan dentro de la banda visual con imágenes de archivo de distinta procedencia, en la que priman, por sobre todas las cosas, fragmentos del film de Raúl Kamffer Mural efímero. El resto del compendio se completa con fotografías periodísticas de la época, imágenes de los cortometrajes documentales de Óscar Menéndez, un collage dedicado a la gráfica del 68 y algunas fotografías de quien registró el desarrollo del mural, junto con la inclusión de citas de José Revueltas y Octavio Paz a modo de títulos dinámicos.

En definitiva, el documental hace hincapié en el compromiso que los artistas tuvieron con el movimiento estudiantil, y es a través de un enlace productivo entre las imágenes registradas in situ y los testimonios orales que el film puede reactivar la memoria sobre el 68 mexicano y la contracultura. Por tanto, aquellas imágenes primigenias de Raúl Kamffer resultan fundamentales, ya que funcionan como un faro que ilumina y anima cualquier discurso acerca de los hechos acaecidos. En este sentido, el testimonio pronunciado por el cineasta Federico Weingartshofer en el mediometraje sintetiza a la perfección la concepción del cine universitario mexicano de finales de los años 60 y refuerza de modo contundente las hipótesis de este trabajo: "El cine no era solamente un medio que tenía fines estéticos, sino que también tenía fines de registro y de trascender al tiempo, y de servir de testimonio". 


\section{Austral Comunicación \\ Volumen 10, número 1 (junio de 2021): 183-206 ISSN (I) 2313-9129. ISSN (E) 2313-9137}

\section{Conclusiones}

A lo largo de este trabajo hemos pretendido asentar una serie de postulados acerca del cortometraje en torno al movimiento estudiantil y el 68 mexicano concebido durante el desarrollo de los acontecimientos. En primer lugar, pudimos observar la predominancia del film breve documental por sobre otra tipología fílmica, como consecuencia de sus posibilidades económicas, la capacidad de aprehensión del receptor y la inmediatez de los hechos. En segunda instancia, constatamos el rol fundamental ejercido desde la década del 50 por la Universidad Nacional Autónoma de México en la renovación estética del cine y su posterior radicalización política, en el marco de la modernización del campo cultural mexicano -compartida a nivel regional- que incluyó la interrelación de las disciplinas artísticas y la acción mancomunada de sus agentes. Así pues, los cortos analizados evidenciaron estas diversas facetas y vislumbraron un uso creativo del lenguaje en la articulación de las bandas de imagen y sonido, con el propósito de contrainformar y concientizar a la sociedad acerca de lo sucesos acaecidos. Es decir que se colocaba en un primer plano la condición del cine como agente de la historia. Asimismo, estas películas dejaron entrever el compromiso conjunto de artistas plásticos e intelectuales para con la causa estudiantil.

Ahora bien, tanto los Comunicados... como Mural efímero apelaron a la capacidad de registro visual del dispositivo fílmico para conformar documentos históricos conscientes de su valor patrimonial en el presente de su confección. Para ello, fue vital la figura de Manuel González Casanova, quien, dentro de la Universidad, estimuló y puso en práctica esta concepción patrimonial.

Finalmente, luego de una reflexión sobre la extensa tradición cinematográfica desplegada alrededor del movimiento estudiantil desde entonces hasta la fecha, y a través del estudio de un caso contemporáneo como Trazos en trozos: Mural efímero, México 68 , pudimos concluir que aquellos cortos inaugurales construyeron una memoria del presente y permitieron edificar un imaginario en torno al 68 mexicano, el cual es revalorizado, reapropiado y reelaborado en cada contexto particular de acuerdo con intereses y determinaciones coyunturales.

En definitiva, la Masacre de Tlatelolco fue el clímax de un hito histórico trascendente en términos globales, que marcó dentro de los confines nacionales el cierre de una etapa a nivel político y cultural. En palabras de Álvaro Vázquez Mantecón (2016):

la experiencia del movimiento estudiantil mexicano de 1968 fue clave para la transformación de las prácticas culturales en el país. Dejaron de tener sentido los proyectos artísticos modernizadores que habían caracterizado el contexto de los años cincuenta y sesenta y que se hallaban en consonancia con la bonanza económica experimentada por el país. (p. 307) 
Javier Cossalter

¿Arte?, ¿documento?, ¿política? La construcción de memoria en el cortometraje alrededor del 68 mexicano

De este modo, resultaría interesante ahondar en cómo la experiencia del $68 \mathrm{im}$ pactó luego en el terreno de la cultura, concretamente en el campo cinematográfico mexicano, al margen de la tradición fílmica que recupera los hechos; devenir tímidamente esbozado en el primer apartado de este trabajo a propósito del desarrollo del cine político en la década del 70. Sin embargo, debido a la magnitud de los acontecimientos y gracias al registro visual de estos, sería pertinente no solo pensar las rupturas ocasionadas en los distintos órdenes del arte y la cultura, sino también considerar los puentes generados. La notable tradición visual local moldeada desde aquel entonces es una muestra de ello. A su vez, se tornaría provechoso explorar de qué forma se rescataron las imágenes acerca del movimiento estudiantil en otros cines por fuera de México, sobre todo en aquellos países latinoamericanos que sufrieron golpes de Estado y Gobiernos represivos. Ambas líneas de investigación se desprenden del recorrido de este artículo y esperamos puedan concretarse en un futuro no tan lejano.

\section{Referencias}

Avilés Cavasola, J.(2015). Símbolos para la memoria: el movimiento estudiantil mexicano de 1968 en su cine (1968-2013) (Tesis de doctorado). Universidad Nacional Autónoma de México, Ciudad de México.

Aviña, R. (2018). ¡No queremos olimpiadas! ¿Queremos revolución! Palabra de Clío.

Burke, P. (2005). Visto y no visto. El uso de la imagen como documento histórico. Editorial Crítica.

Colin, C. (2014). Patrimonio del presente: fundamentos y límites. En La noción de patrimonio en Ciencias Sociales: controversias, usos y abusos. Universidad de Chile.

Cossalter, J. (2017). Experimentación e innovación en el cortometraje documental latinoamericano moderno: las experiencias de Brasil, Cuba y México. Kamchatka. Revista de análisis cultural, (10), 489-511. https://ojs.uv.es/index.php/kamchatka/ article/view/10551.

Cossalter, J. (2018). El cortometraje latinoamericano moderno. Experimentación estética y vínculos con el campo cultural en Argentina, Cuba y México. Anales del Instituto de Investigaciones Estéticas, 40(113), 9-39. http://www.analesiie.unam.mx/ index.php/analesiie/article/view/2654.

Cossalter, J. (2019). El cortometraje como impulsor primigenio de la modernidad cinematográfica en Brasil y en Chile. Entre la pesquisa estética y el compromiso social. Meridional. Revista Chilena de Estudios Latinoamericanos, (12), 17-54. https://meridional.uchile.cl/index.php/MRD/article/view/52424.

Cossalter, J. (2020). Hibridación, intermedialidad y performance en el cortometraje latinoamericano moderno. PragMATIZES - Revista Latino-Americana de Estudos em Cultura, 10(19), 274-297. https://doi.org/10.22409/pragmatizes.v10i19.40660. 


\section{Austral Comunicación \\ Volumen 10, número 1 (junio de 2021): 183-206 ISSN (I) 2313-9129. ISSN (E) 2313-9137}

De la Vega Alfaro, E. (2015). Importancia y significación del grupo Nuevo Cine en la cultura fílmica mexicana. En Elizalde, L. (Coord.), Nuevo Cine (pp. 9-27). DGE Equilibrista.

Driben, L. (2012). La generación de la ruptura y sus antecedentes. Fondo de Cultura Económica.

Ferrer Andrade, M. G., Aurrecoechea Hernández, J. M., Rodríguez Rodríguez, I., Loewe, S., De Lara Rangel, M. C., Vázquez Mantecón, Á., Avilés Cavasola, J., Álvarez Gómez, A. (2018). El grito: memoria en movimiento. Universidad Nacional Autónoma de México.

Ferro, M. (1980). Cine e Historia. Editorial Gustavo Gili.

Galindo, J. (2017). La conferencia de Chapultepec (1945): el Nacionalismo económico latinoamericano frente a la política librecambista de Estados Unidos. América Latina en la Historia Económica, 24(2), 35-58. https://doi.org/10.18232/alhe. v24i2.800.

Gilman, C. (2003). Entre la pluma y el fusil. Debates y dilemas del escritor revolucionario en América latina. Siglo XXI Editores.

Guarini, C. (2002). Memoria social e imagen. Cuadernos de Antropología Social, (15), 133-123. http://revistascientificas.filo.uba.ar/index.php/CAS/article/view/4620.

Jelin, E. (2002). Memorias de la represión. Los trabajos de la memoria. Siglo XXI Editores.

Lara López, E. L. (2005). La fotografía como documento histórico-artístico y etnográfico: una epistemología. Revista de Antropología Experimental, (5), 1-28. https://revistaselectronicas.ujaen.es/index.php/rae/article/view/2068.

Mestman, M. (2014). Tlatelolco 1968 y otros gritos subalternos del cine latinoamericano. Clepsidra. Revista Interdisciplinaria de Estudios sobre Memoria, 1(1), 52-67. http:// ppct.caicyt.gov.ar/index.php/clepsidra/article/view/MESTMAN.

Mestman, M. (2016). Presentación. Las rupturas del 68 en el cine de América Latina: Contracultura, experimentación y política. En Mestman, M. (Coord.), Rupturas del 68 en el cine de América Latina (pp. 7-61). Ediciones Akal.

Miquel, A. (2010). Nuevo Cine. En Elizalde Valdés, L. (Coord.), Revistas culturales latinoamericanas 1960-2008 (pp. 43-55). Universidad Autónoma del Estado de Morelos.

Monsiváis, C. (1976). Notas sobre la cultura mexicana en el siglo XX. En Cosío Villegas, D. (Coord.), Historia General de México (pp. 1375-1548). El Colegio de México.

Paranaguá, P. A. (2003). Tradición y modernidad en el cine de América Latina. Fondo de Cultura Económica.

Ramírez Miranda, J. (2015). Cortometraje documental mexicano, años sesenta: las vías de la politización. Imagofagia, (12), 1-28. http://www.asaeca.org/imagofagia/index. php/imagofagia/article/view/821. 
Rodríguez Álvarez, G. (2009). Manuel González Casanova.Pionero del cine universitario. Universidad de Guadalajara.

Rajewsky, I. O. (2005). Intermediality, Intertextuality, and Remediation: A Literary Perspective on Intermediality. Intermédialités, (6), 43-64. https://www.erudit.org/ en/journals/im/2005-n6-im1814727/1005505ar/.

Sánchez Noriega, J. L. (2008). De la 'película histórica' al cine de la memoria. En Camarero, G., De las Heras, B. y De Cruz, V. (Eds.), Una ventana indiscreta. La historia desde el cine (pp. 87-95). Ediciones J. C.

Sorlin, P. (2008). Cine e Historia, una relación que hace falta repensar. En Camarero, G., De las Heras, B. y De Cruz, V. (Eds.), Una ventana indiscreta. La historia desde el cine (pp. 19-31). Ediciones J. C.

UNESCO. (27 de octubre de 1980). Recomendación sobre la Salvaguardia y la Conservación de las Imágenes en Movimiento. http://portal.unesco.org/es/ev.phpURL_ID $=13139 \&$ URL_DO=DO_TOPIC\&URL_SECTION=201.html.

Vázquez Mantecón,A. (2016). México. El 68 cinematográfico. En Mestman, M.(Coord.), Rupturas del 68 en el cine de América Latina (pp. 285-310). Ediciones Akal.

Vázquez Mantecón, A. (2018). Fuera de campo: otros registros cinematográficos del movimiento estudiantil. En Ferrer Andrade, M. G., Aurrecoechea Hernández, J. M., Rodríguez Rodríguez, I., Loewe, S., De Lara Rangel, M. C., Vázquez Mantecón, Á., Avilés Cavasola, J., Álvarez Gómez, A., El grito: memoria en movimiento (pp. 6987). Universidad Nacional Autónoma de México.

Wood, D. M. J. (2015). Renovación, patrimonio y cultura cinematográfica en México, 1952-1967. En Eder, R. (Ed.), Genealogías del arte contemporáneo en México 1952-1967 (pp. 106-114). Ciudad de México: Universidad Nacional Autónoma de México. 